\title{
The effects of ruthenium-oxidation states on Ru dissolution in PtRu thin-film electrodes
}

\author{
Yejun Park, Byungjoo Lee, Chunjoong Kim, Yuhong Oh, Seunghoon Nam, and Byungwoo Park ${ }^{\mathrm{a})}$ \\ Department of Materials Science and Engineering, and Research Center for Energy Conversion and Storage, \\ Seoul National University, Seoul 151-744, Korea
}

(Received 9 September 2008; accepted 27 May 2009)

\begin{abstract}
The effects of ruthenium $(\mathrm{Ru})$-oxidation states were investigated on $\mathrm{Ru}$ dissolution from PtRu thin-film electrodes, with the 200 cycles between 0.4 and $1.05 \mathrm{~V}$ (versus normal hydrogen electrode). The Ru-oxidation states of the PtRu thin films were systematically modified by an anodic (oxidation) treatment. The anodic-treated PtRu electrodes, whose methanol-oxidation activity was similar to untreated electrodes before the 200 cycles, showed a remarkable decrease in methanol oxidation after the cycles, because of the $\mathrm{Ru}$ dissolution from the PtRu surface. The results suggest that the Ru-oxide species are the origin of Ru dissolution in the PtRu alloy.
\end{abstract}

\section{INTRODUCTION}

Direct-methanol fuel cells (DMFCs) have attracted considerable attention as power sources for portable electronic devices because of their high energy density, easy handling of liquid, low operating temperatures, etc. ${ }^{1-3}$ In general, the platinum-ruthenium $(\mathrm{PtRu})$ alloy is currently considered to be the most promising DMFC anode catalyst for methanol oxidation. ${ }^{4-7}$

Recently, the stability of electrocatalysts has received a great deal of attention, because the electrode performance can degrade after the long-term operation of fuel cells, due to the dissolution of the noble metal-based catalysts and the aggregation of catalyst nanoparticles. ${ }^{8}$ In particular, Piela et al. ${ }^{9}$ reported on DMFCs that Ru from the $\mathrm{PtRu}$ anode can cross through the proton exchange membrane (Nafion) and settle on the Pt cathode. This $\mathrm{Ru}$ crossover, which originates in $\mathrm{Ru}$ dissolution from the $\mathrm{PtRu}$ anode, can degrade the performance of all the major components of the fuel cell. It has been reported that the anode potential of a DMFC can vary from $\sim 0.4$ to $\sim 1.0 \mathrm{~V}$ [versus normal hydrogen electrode (NHE)] during on-off operations, and the $\mathrm{Ru}$ dissolution is caused by cycling between the reduced and oxidized states of $\mathrm{Ru}$ [thermodynamically, metallic $\mathrm{Ru}$ oxidizing to $\mathrm{Ru}(\mathrm{OH})_{3}$, and $\mathrm{RuO}_{2} \cdot 2 \mathrm{H}_{2} \mathrm{O}$, respectively, at 0.74 and $0.94 \mathrm{~V}$ versus $\mathrm{NHE}] .{ }^{10}$ Accordingly, our group has recently investigated the effects of a metal-phosphate coating layer on the block of Ru crossover. ${ }^{11}$ However, the origin of Ru dissolution from the PtRu alloy is not completely elucidated. Therefore, it is important to identify the mechanisms of $\mathrm{Ru}$ dissolution from PtRu-alloy anodes.

\footnotetext{
a) Address all correspondence to this author.

e-mail: byungwoo@snu.ac.kr

DOI: 10.1557/JMR.2009.0331
}

The oxophilic Ru metals as pair sites of Pt metals allow the water dissociation for the promotion of methanol activation, and the adsorption of $\mathrm{OH}$ species on the $\mathrm{Ru}$ sites facilitates the oxidation of $\mathrm{CO}$ on adjacent $\mathrm{Pt}$ sites. ${ }^{12}$ The oxophilic properties of $\mathrm{Ru}$ also allow the easy formation of oxide species, and Ru oxides are present on the PtRu alloy surface at a significant fraction. ${ }^{13}$ Enhanced proton transport in the hydrous $\mathrm{Ru}$ oxides $\left(\mathrm{RuO}_{2} \cdot \mathrm{H}_{2} \mathrm{O}\right.$ or $\left.\mathrm{RuO}_{x} \mathrm{H}_{y}\right)$ in $\mathrm{Pt}-\mathrm{RuO}_{2}$ has been reported. ${ }^{14}$ Recently, it was also reported that the mixture of Pt metal and hydrous Ru oxide phase shows better performance than a bimetallic alloy. ${ }^{15}$ In this letter, the effects of rutheniuim-oxidation states were studied on $\mathrm{Ru}$ dissolution from PtRu thin-film electrodes.

\section{EXPERIMENTAL}

The PtRu thin-film alloy was deposited on indium tin oxide (ITO)-coated glass (Samsung Corning, Cheonan, Korea) by radio frequency magnetron sputtering using $\mathrm{Pt}$ and Ru targets. The sputtering was performed under an $\mathrm{Ar}$ atmosphere with a flow rate of 30 standard cubic centimeters per minute $(\mathrm{sccm})$ at an operating pressure of 10 mTorr and room temperature (RT). The Ru-oxidation states of the PtRu thin films were modified with an anodic treatment in a $0.5 \mathrm{M} \mathrm{H}_{2} \mathrm{SO}_{4}$ solution at $1.1 \mathrm{~V}$ (versus $\mathrm{NHE}$ ) for 15 or $30 \mathrm{~min}$ at $50{ }^{\circ} \mathrm{C}$. The Ru dissolution from the untreated and anodic-treated PtRu thin-film electrodes was examined with a repeated potential cycling in a $0.5 \mathrm{M}$ $\mathrm{H}_{2} \mathrm{SO}_{4}$ solution between 0.4 and $1.05 \mathrm{~V}$ at RT and a scan rate of $500 \mathrm{mV} / \mathrm{s}$ for 200 cycles.

The electrochemical measurements were made with a conventional three-electrode electrochemical system at RT. The PtRu thin-film electrodes, the Pt wire, and the saturated calomel electrode served as the working, counter, and reference electrodes, respectively. All the 
potentials have been converted and are presented versus NHE in this article. The electrochemical properties of the PtRu thin-film electrodes were determined by cyclic voltammetry at potentials ranging from 0.06 to $0.47 \mathrm{~V}$, at a scan rate of $50 \mathrm{mV} / \mathrm{s}$ in $0.5 \mathrm{M} \mathrm{H}_{2} \mathrm{SO}_{4}$. The methanol-oxidation activities on these electrodes were investigated in a solution of $0.5 \mathrm{M} \mathrm{H}_{2} \mathrm{SO}_{4}$ and $2 \mathrm{M} \mathrm{CH}_{3} \mathrm{OH}$ at a scan rate of $50 \mathrm{mV} / \mathrm{s}$. All the solutions were purged with $\mathrm{N}_{2}$ gas for $30 \mathrm{~min}$ before each electrochemical measurement. The chemical bonding states and approximate surface compositions of the $\mathrm{Pt}$ and $\mathrm{Ru}$ were analyzed by x-ray photoelectron spectroscopy (XPS). The nanostructures of the PtRu thin films were determined by $\mathrm{x}$-ray diffraction, and the surface morphologies were observed with atomic force microscopy (AFM). Before each surface analysis, the electrochemically treated samples were washed with deionized water and dried under vacuum.

\section{RESULTS AND DISCUSSION}

Figure 1 shows the XPS spectra of the Ru $3 p_{3 / 2}$ core levels of the PtRu thin films. The spectra show that the Ru-oxidation states were modified significantly by the anodic treatment in the $\mathrm{H}_{2} \mathrm{SO}_{4}$ solution at $1.1 \mathrm{~V}$. The peaks located at 461.1, 462.2, 463.8, and $466.9 \mathrm{eV}$ can be identified with metallic $\mathrm{Ru}, \mathrm{RuO}_{2}$, hydrous $\mathrm{RuO}_{2}$, and $\mathrm{RuO}_{3}$, respectively. ${ }^{16,17}$ As shown in Fig. 1(a), the $\mathrm{Ru}$-oxidation states of the untreated PtRu electrodes con-

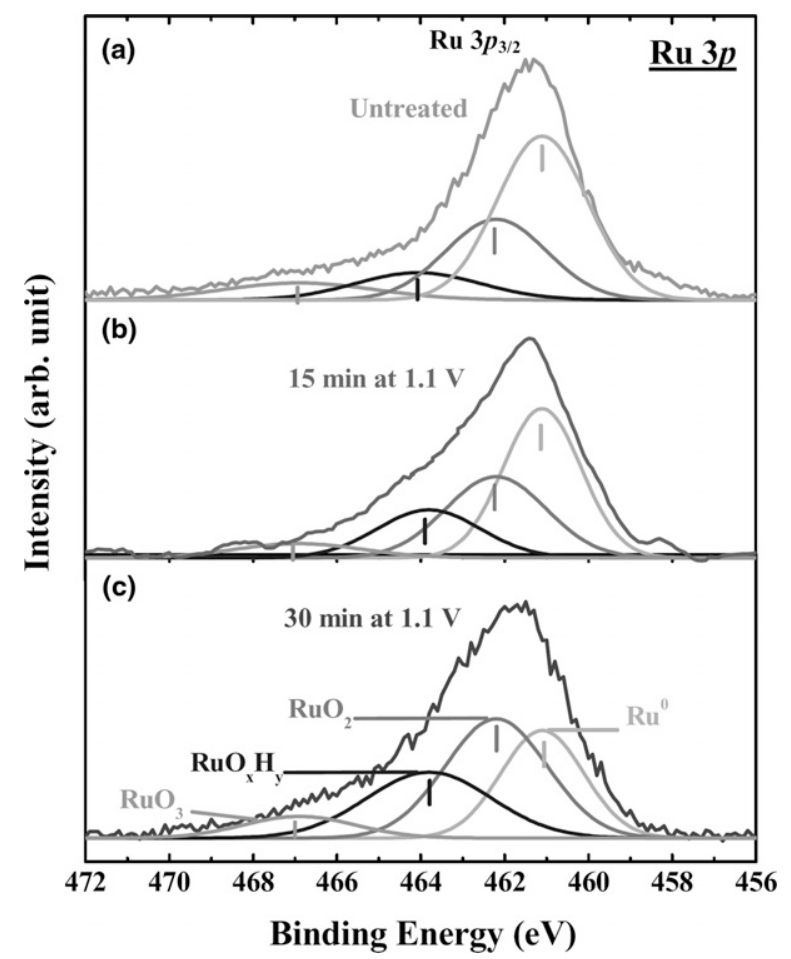

FIG. 1. XPS spectra of Ru $3 p_{3 / 2}$ for (a) the untreated PtRu, and anodic-treated PtRu thin films for (b) $15 \mathrm{~min}$ and (c) $30 \mathrm{~min}$ at $1.1 \mathrm{~V}$. sist of metallic $\mathrm{Ru}(\sim 50 \%), \mathrm{RuO}_{2}(\sim 29 \%)$, hydrous $\mathrm{RuO}_{2}(\sim 12 \%)$, and $\mathrm{RuO}_{3}(\sim 9 \%)$. [These values were estimated by XPS fitting to provide a qualitative estimate of the distribution of the Ru-oxidation states. The peaks were fitted using a Doniach-Sunjic line shape (intensity and width), ${ }^{18}$ with the four oxidation-state peak positions fixed and with the fitting procedure performed with an XPS curve simulator. ${ }^{19,20}$ ] After the anodic treatment for $30 \mathrm{~min}$, the relative amount of metallic $\mathrm{Ru}$ decreased to $\sim 28 \%$, while the amounts of $\mathrm{RuO}_{2}$ and hydrous $\mathrm{RuO}_{2}$ increased to $\sim 38 \%$ and $\sim 26 \%$, respectively. The increase in the concentration of Ru-oxide species was attributed to the formation and accumulation of irreversible $\mathrm{Ru}$ oxides with bridged oxygen, $\mathrm{OH}$, and water, during the anodic treatment. ${ }^{21}$ It should be noted, however, that the oxidation states of Pt were not significantly altered by the anodic treatment, as shown in Fig. S1.

Table I shows the active surface areas of the untreated $\mathrm{PtRu}$ and the anodic-treated PtRu, as determined with the hydrogen-desorption $(\mathrm{Pt}-\mathrm{H})$ method from the cyclic voltammograms in the $\mathrm{H}_{2} \mathrm{SO}_{4}$ solution before 200 cycles (Fig. S2). ${ }^{22}$ The increase in the active surface area following the anodic treatments may be due to an increase in surface roughness that resulted from the formation of irreversible Ru-oxide species. It should be noted that the anodic treatment of the PtRu alloy for $30 \mathrm{~min}$ at $1.1 \mathrm{~V}$ does not considerably alter the surface composition.

The efficiency of the untreated PtRu and the anodictreated PtRu electrodes for methanol oxidation was evaluated before and after the 200 cycles, as shown in Fig. 2. The current densities in the methanol oxidation were

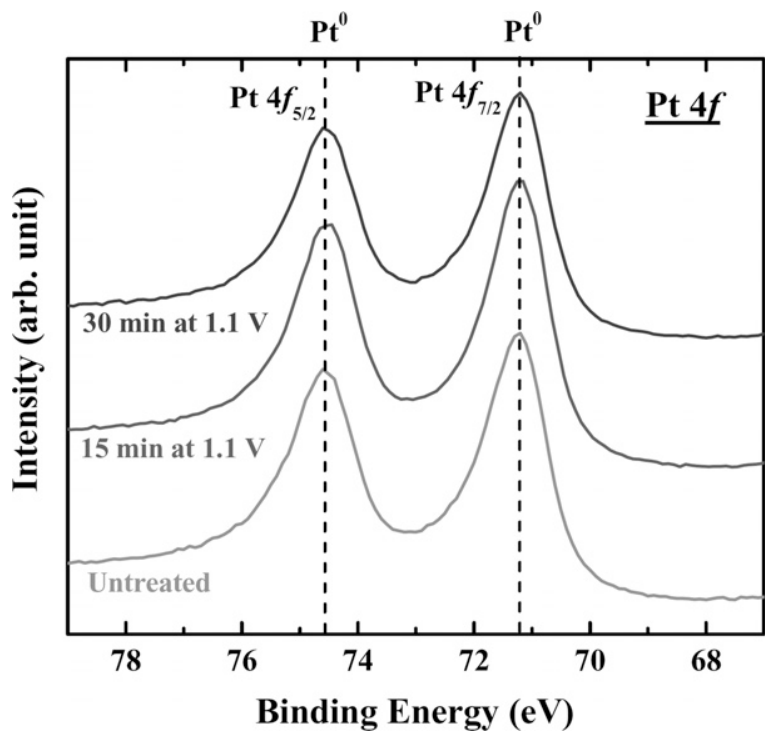

FIG. S1. XPS spectra of Pt $4 f$ for the untreated and anodic-treated PtRu thin films on the ITO-coated glass. The marked peak positions are from the standard samples of metallic Pt. 
TABLE I. The active surface areas were determined using the hydrogen-desorption $(\mathrm{Pt}-\mathrm{H})$ method (as shown in Fig. S2), and the approximate surface compositions were estimated by XPS to serve as a qualitative comparison.

\begin{tabular}{|c|c|c|c|c|}
\hline \multirow[b]{2}{*}{ Anodic treatment } & \multicolumn{2}{|c|}{ Before 200 cycles } & \multicolumn{2}{|c|}{ After 200 cycles } \\
\hline & $\begin{array}{l}\text { Active surface area } \\
\text { (per } 1 \mathrm{~cm}^{2} \text { sample) }\end{array}$ & $\begin{array}{l}\text { Surface composition } \\
\text { Pt: Ru (at.\%) }\end{array}$ & $\begin{array}{l}\text { Active surface area } \\
\text { (per } 1 \mathrm{~cm}^{2} \text { sample) }\end{array}$ & $\begin{array}{l}\text { Surface composition } \\
\text { Pt: Ru (at.\%) }\end{array}$ \\
\hline Untreated & $1.21 \mathrm{~cm}^{2}$ & $65: 35$ & $1.41 \mathrm{~cm}^{2}$ & $68: 32$ \\
\hline $15 \mathrm{~min}$ at $1.1 \mathrm{~V}$ & $1.37 \mathrm{~cm}^{2}$ & $65: 35$ & $1.58 \mathrm{~cm}^{2}$ & 70: 30 \\
\hline $30 \mathrm{~min}$ at $1.1 \mathrm{~V}$ & $1.45 \mathrm{~cm}^{2}$ & $66: 34$ & $1.99 \mathrm{~cm}^{2}$ & $72: 28$ \\
\hline
\end{tabular}

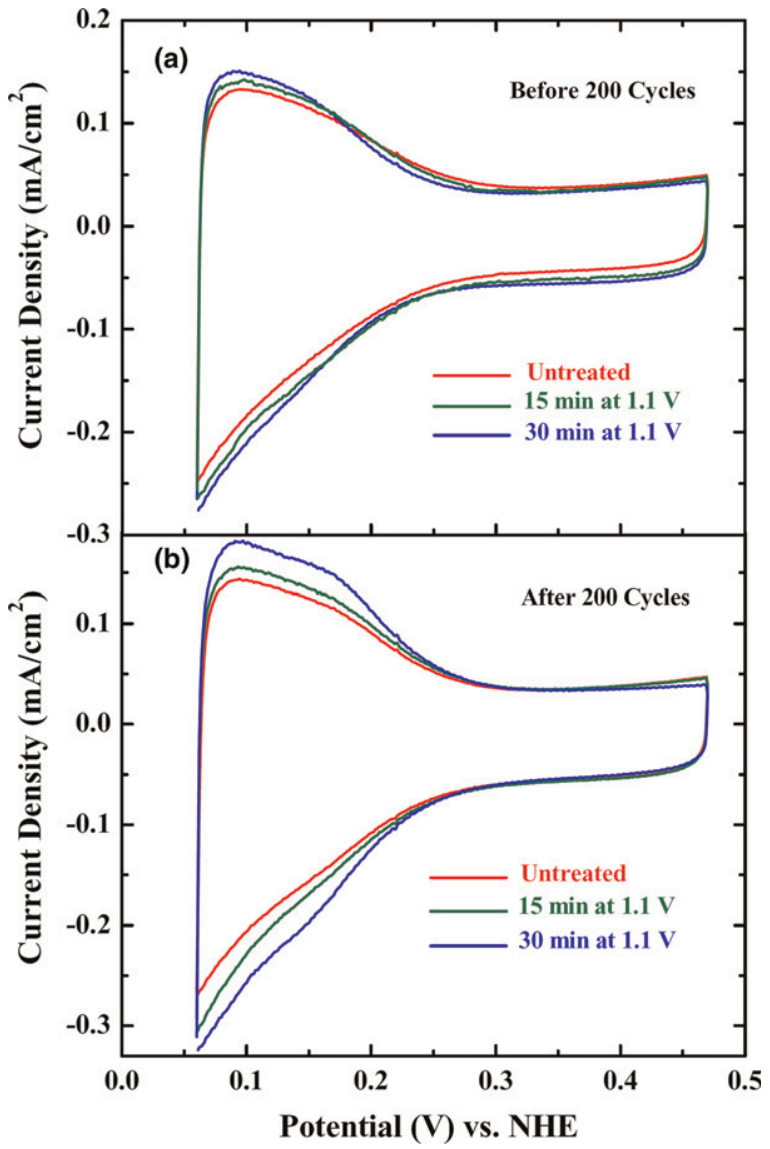

FIG. S2. Cyclic voltammograms of thin-film electrodes in the $0.5 \mathrm{M}$ $\mathrm{H}_{2} \mathrm{SO}_{4}$ solution at a scan rate of $50 \mathrm{mV} / \mathrm{s}$ : (a) before and (b) after 200 cycles. (color online)

normalized to the active surface area. The insets in Fig. 2 show the same oxidation data, normalized to the $1 \mathrm{~cm}^{2}$ sample area. Before the cycles, the anodic-treated PtRu electrodes and the untreated PtRu electrodes have similar methanol-oxidation activities. It appears that the $\mathrm{Ru}$ oxide species formed as a result of the anodic treatments can contribute to methanol-oxidation activities. ${ }^{15,23}$

After 200 cycles $(0.4-1.05 \mathrm{~V}$ at $500 \mathrm{mV} / \mathrm{s})$, the untreated PtRu electrodes showed a small decrease in methanol-oxidation activity. However, the anodic-treated $\mathrm{PtRu}$ electrodes, whose activity was similar to that of the untreated electrodes before the 200 cycles, show a remarkable decrease in methanol oxidation. The surface

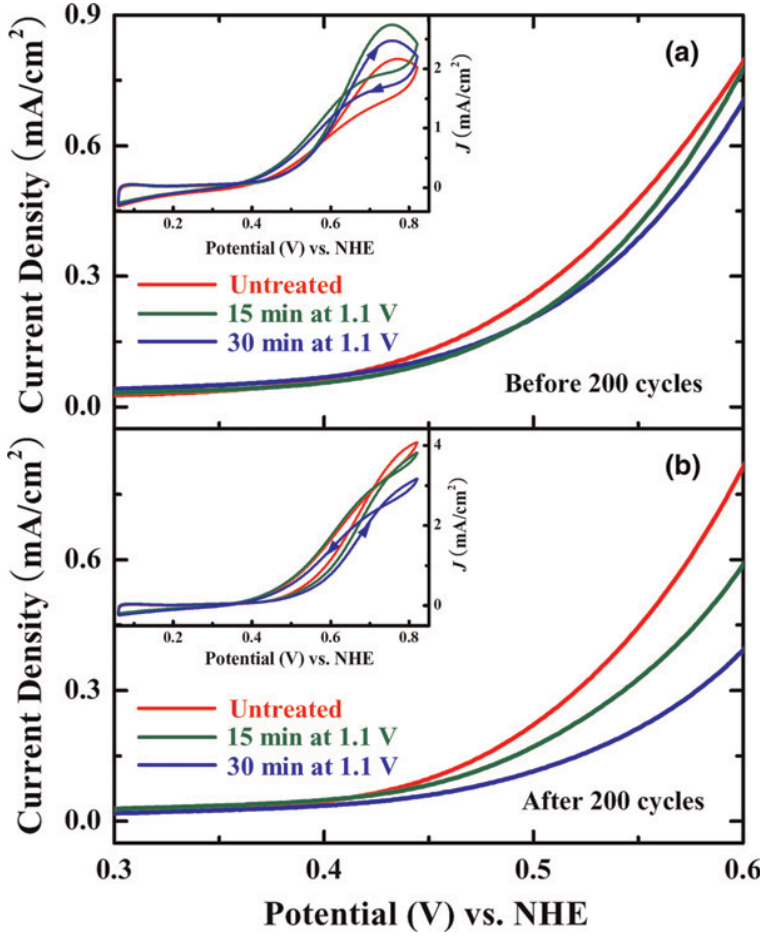

FIG. 2. Current densities versus applied potentials, which were normalized to the active surface area (Table I), for the untreated and anodic-treated PtRu thin-film electrodes in $0.5 \mathrm{M} \mathrm{H}_{2} \mathrm{SO}_{4}+2 \mathrm{M}$ $\mathrm{CH}_{3} \mathrm{OH}$ : (a) before and (b) after 200 cycles. The insets show methanol oxidation normalized to the $1 \mathrm{~cm}^{2}$ sample area. (color online)

areas of the electrodes increased because of the exposure of the Pt centers that resulted from the Ru having been depleted from the PtRu alloy after 200 cycles (Table I and Fig. S2). This Ru depletion is also confirmed by XPS estimates of the composition of Pt and Ru in the PtRu surface. Therefore, the decrease in methanol-oxidation activity [Fig. 2(b)] appears to be attributable to the $\mathrm{Ru}$ dissolution from the PtRu surface after 200 cycles.

Figure 3 shows the Ru $3 p_{3 / 2}$ peak in the XPS spectrum for the $\mathrm{PtRu}$ electrodes that were anodic-treated for $30 \mathrm{~min}$, both before and after 200 cycles. The relative amounts of $\mathrm{RuO}_{2}$ and hydrous $\mathrm{RuO}_{2}$ decreased after the 200 cycles, which implies that the $\mathrm{Ru}$ dissolution from the PtRu alloy is caused by the Ru-oxide species, namely, the non-alloyed and segregated $\mathrm{Ru}$ oxides in the PtRu surface (see Fig. S3). For a homogeneous (solid-solution) metallic PtRu alloy, the dissolution potential is expected 


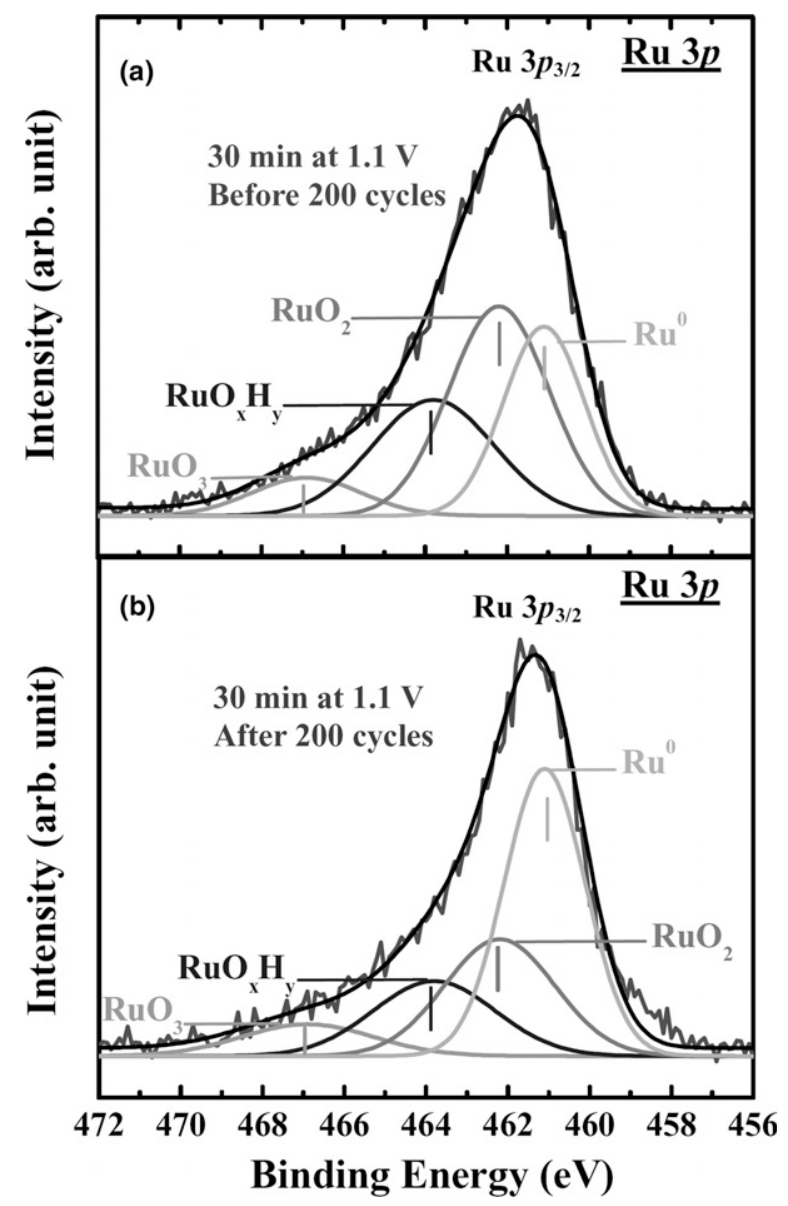

FIG. 3. XPS spectra of the Ru $3 p_{3 / 2}$ for the anodic-treated PtRu electrodes at $1.1 \mathrm{~V}$ for $30 \mathrm{~min}$ : (a) before [same as Fig. 1(c)] and (b) after 200 cycles.

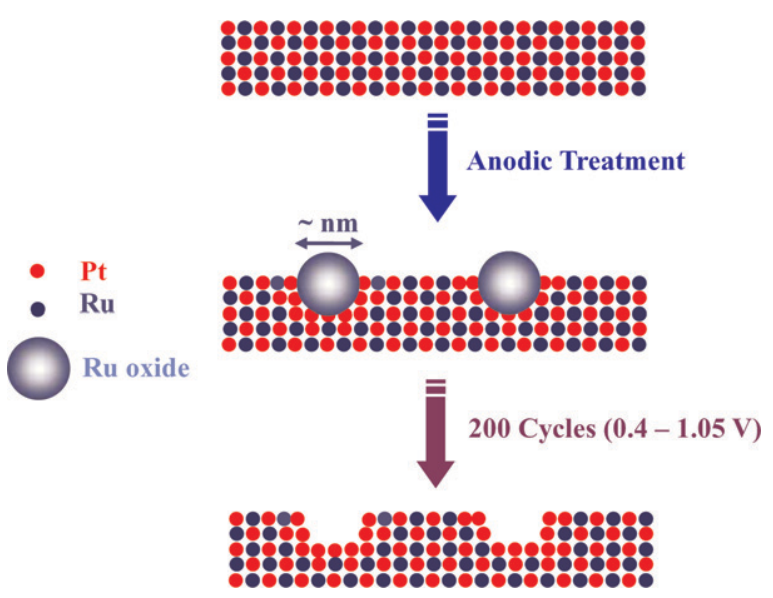

FIG. S3. Schematic illustration of the proposed mechanism of Ru dissolution from the PtRu surface. (color online)

to increase more than the Ru redox potential because of the increase in the critical potential for the dissolution in alloy. ${ }^{24,25} \mathrm{Ru}$ dissolution from the PtRu alloy during fuelcell operation may be caused by the Ru-oxide species

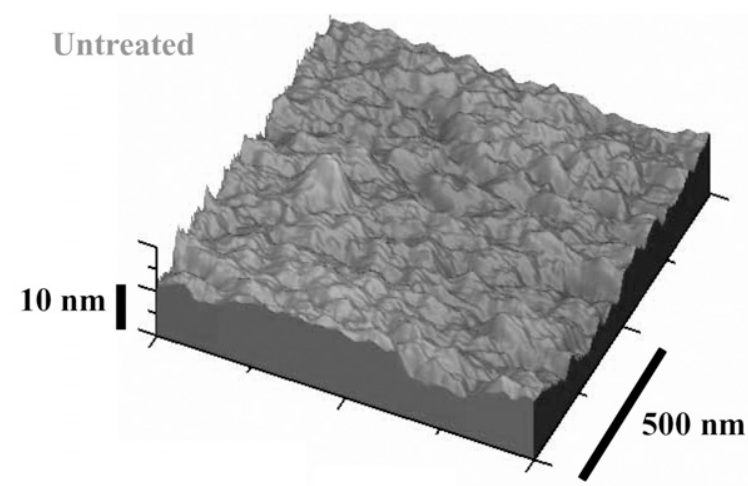

(a)

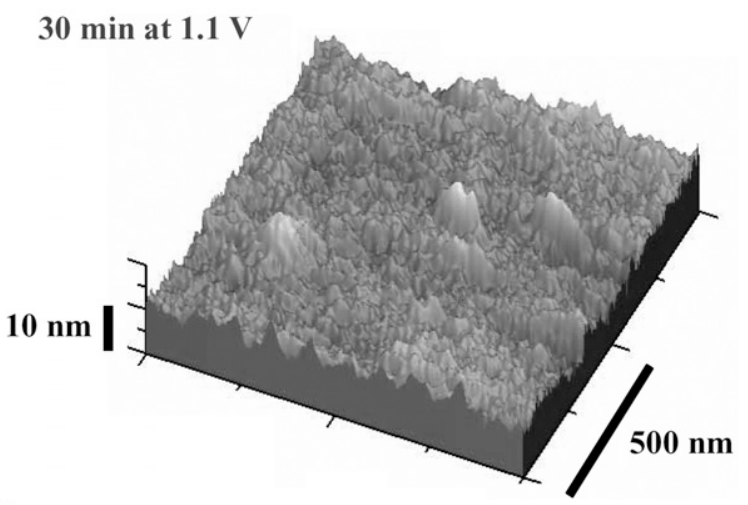

(b)

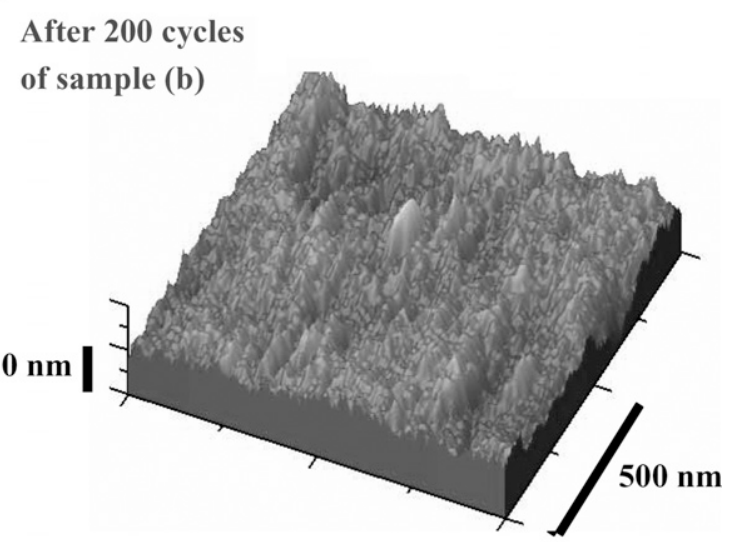

(c)

FIG. 4. AFM images of (a) the untreated, (b) anodic-treated PtRu for $30 \mathrm{~min}$ at $1.1 \mathrm{~V}$, and (c) after 200 cycles of sample (b).

rather than by the metallic Ru. Therefore, the segregated $\mathrm{Ru}$-oxide species in the PtRu surface have disadvantages in enhancing the long-term stability of the PtRu anode for methanol oxidation.

The surface morphology of the untreated PtRu thin films is shown in Fig. 4(a) by AFM. The surface of the as-deposited PtRu thin films was relatively smooth, with a lateral roughness (root-mean-square peak-to-peak distance) of $\sim 50 \mathrm{~nm}$, and a vertical roughness (rootmean-square peak-to-valley height) of $\sim 2 \mathrm{~nm}$. After the anodic treatments, the formation of segregated Ru-oxide species on the PtRu surface caused the surface to become rough, with a lateral roughness of $\sim 10 \mathrm{~nm}$ and a 
vertical roughness of $\sim 3 \mathrm{~nm}$ [Fig. 4(b)]. After the 200 cycles, the surface lateral roughness and vertical roughness remained almost the same [Fig. 4(c)] despite the dissolution of segregated Ru-oxide species on the PtRu surface.

$\mathrm{Ru}$ oxidation can occur on the PtRu surface, and these oxide precipitates make the surface rougher than before. The decreased peak-to-peak distance from $\sim 50$ to $\sim 10 \mathrm{~nm}$ can be attributed to the existence of sites with Ru-oxide precipitates. Because of the dissolution of Ru oxides, the surface roughness looks the same after 200 cycles. This rough estimation indicates that the size of the segregated $\mathrm{Ru}$-oxide species is on a nanometer scale. These are illustrated in Fig. S3.

\section{CONCLUSIONS}

The effects of Ru-oxidation states were investigated on the $\mathrm{Ru}$ dissolution from $\mathrm{PtRu}$ thin-film electrodes to compare the alloyed $\mathrm{Ru}$ metal with several $\mathrm{Ru}$-oxide species. The Ru-oxidation states in the PtRu thin-film electrodes were modified systematically by the anodic treatment. The surface of PtRu thin-film electrodes was altered and Ru-oxide species were formed. However, these oxide species were more easily dissolved than the alloyed $\mathrm{Ru}$ metal. Therefore, we suggest that the $\mathrm{Ru}$ dissolution in the PtRu alloy is attributable to the segregated Ru-oxide species in the PtRu surface. For the long-term stability of Ru-based catalysts, further studies of various Ru oxides should be pursued, on specific comparison between hydrous and anhydrous Ru oxide.

\section{ACKNOWLEDGMENTS}

This work was supported by the Korea Research Foundation (2009-0062952) through the Research Center for Energy Conversion and Storage (RCECS) and by the Korea Science and Engineering Foundation (R31-2008000-10075-0) through the World Class University (WCU).

\section{REFERENCES}

1. L. Carrette, K.A. Friedrich, and U. Stimming: Fuel cells-Fundamentals and applications. Fuel Cells 1, 5 (2001).

2. E. Reddington, A. Sapienza, B. Gurau, R. Viswanathan, S. Sarangapani, E.S. Smotkin, and T.E. Mallouk: Combinatorial electrochemistry: A highly parallel, optical screening method for discovery of better electrocatalysts. Science 280, 1735 (1998).

3. B. Lee, C. Kim, Y. Park, T-G. Kim, and B. Park: Nanostructured platinum/iron phosphate thin-film electrodes for methanol oxidation. Electrochem. Solid-State Lett. 9, E27 (2006).

4. M. Watanabe and S. Motoo: Electrocatalysis by ad-atoms: Part II. Enhancement of the oxidation of methanol on platinum by ruthenium ad-atoms. J. Electroanal. Chem. 60, 267 (1975).

5. H. Gasteiger, N. Markovic, P. Ross, and E.J. Cairns: Methanol electrooxidation on well-characterized platinum-ruthenium bulk alloys. J. Phys. Chem. 97, 12020 (1993).
6. J. Goodenough, R. Manoharan, A.K. Shukla, and K.V. Rameshand: Intra-alloy electron transfer and catalyst performance: A spectroscopic and electrochemical study. Chem. Mater. 1, 391 (1989).

7. E. Herrero, K. Franaszczuk, and A. Wiekowski: Crystal planes of platinum: An integrated voltammetric and chronoamperometric study. J. Phys. Chem. 98, 5074 (1994).

8. C. Kim, B. Lee, Y. Park, B. Park, J. Lee, and H. Kim: Ironphosphate/platinum/carbon nanocomposites for enhanced electrocatalytic stability. Appl. Phvs. Lett. 91, 113101 (2007).

9. P. Piela, C. Eickes, E. Brosha, F. Garzon, and P. Zelenay: Ruthenium crossover in direct methanol fuel cell with $\mathrm{Pt}-\mathrm{Ru}$ black anode. J. Electrochem. Soc. 151, A2053 (2004).

10. W.L. Holstein and H.D. Rosenfeld: In-situ X-ray absorption spectroscopy study of Pt and Ru chemistry during methanol electrooxidation. J. Phvs. Chem. B 109, 2176 (2005).

11. Y. Park, B. Lee, C. Kim, J. Kim, and B. Park: The effects of ironphosphate coating on Ru dissolution in the PtRu thin-film electrodes. J. Mater. Res. 24, 140 (2009).

12. F. Liu, Q. Yan, W.J. Zhou, X.S. Zhao, and J.Y. Lee: High regularity porous oxophilic metal films on $\mathrm{Pt}$ as model bifunctional catalysts for methanol oxidation. Chem. Mater. 18, 4328 (2006).

13. H. Li, G. Sun, Y. Gao, Q. Jiang, Z. Jia, and Q. Xin: Effect of reaction atmosphere on the electrocatalytic activities of $\mathrm{Pt} / \mathrm{C}$ and $\mathrm{PtRu} / \mathrm{C}$ obtained in a polyol process. J.Phvs. Chem. C 111. 15192 (2007).

14. W. Dmowski, T. Egami, K.E. Swider-Lyons, C.T. Love, and D.R. Rolison: Local atomic structure and conduction mechanism of nanocrystalline hydrous $\mathrm{RuO}_{2}$ from x-ray scattering. J. Phvs. Chem. B 106, 12677 (2002).

15. J.W. Long, R.M. Stroud, K.E. Swider-Lyons, and D.R. Rolison: How to make electrocatalysts more active for direct methanol oxidation-avoid PtRu bimetallic alloys. J. Phys. Chem. B $\mathbf{1 0 4}$ $9772(2000)$.

16. A. Arico, P. Creti, H. Kim, R. Mantegna, N. Giordano, and V. Antonucci: Analysis of the electrochemical characteristics of a direct methanol fuel cell based on a $\mathrm{Pt}-\mathrm{Ru} / \mathrm{C}$ anode catalyst. J. Electrochem. Soc. 143, 3950 (1996).

17. X. Zhang and K-Y. Chan: Water-in-oil microemulsion synthesis of platinum-ruthenium nanoparticles, their characterization and electrocatalytic properties. Chem. Mater. 15, 451 (2003).

18. S. Doniach and M. Sunjic: Many-electron singularity in x-ray photoemission and $\mathrm{x}$-ray line spectra from metals. J.Phvs. C: Solid State Phvs. 3, 285 (1970).

19. P.N.K. Deenapanray, M. Petravić, K-J. Kim, B. Kim, and G. Li: Compositional changes on GaN surfaces under low-energy ion bombardment studied by synchrotron-based spectroscopies. Appl. Phvs. Lett. 83, 4948 (2003).

20. B.P. Hahn, R.A. May, and K.J. Stevenson: Electrochemical deposition and characterization of mixed-valent rhenium oxide films prepared from a perrhenate solution. Langmuir 23, 10837 (2007).

21. K-H. Chang and C-C. Hu: Coalescence inhibition of hydrous $\mathrm{RuO}_{2}$ crystallites prepared by a hydrothermal method. Appl. Phys. Lett. 88, 193102 (2006).

22. T.J. Schmidt, H.A. Gasteiger, G.D. Stäb, P.M. Uraban, D.M. Kolb, and R.J. Behm: Characterization of high surface area electrocatalysts using a rotating disk electrode configuration. J. Electrochem. Soc. 145, 2354 (1998).

23. Q. Lu, B. Yang, L. Zhuang, and J. Lu: Anodic activation of PtRu/C catalysts for methanol oxidation. J.Phvs. Chem. B 109, 1715 (2005).

24. J. Erlebacher, M.J. Aziz, A. Karma, N. Dimitrov, and K. Sieradzki: Evolution of nanoporosity in dealloying. Nature 410, 450 (2001)

25. C. Kim, Y. Park, C. Nahm, and B. Park: Formation of nanoporous $\mathrm{Pt}$ thin films by electrochemical dissolution. Electron. Mater. Lett. 4, 75 (2008). 